\title{
THE
}

\section{Who Are Resource Nonusers and What Can They Tell Us About Nonuse Values? Decomposing User and Nonuser Willingness to Pay for Coastal Wetland Restoration}

\author{
Robert J. Johnston \\ James J. Opaluch \\ University of Rhode Island, JIMO@URI.EDU \\ Gisele Magnusson \\ Marisa J. Mazzotta
}

Follow this and additional works at: https://digitalcommons.uri.edu/enre_facpubs

Part of the Natural Resources and Conservation Commons

Terms of Use

All rights reserved under copyright.

\footnotetext{
Citation/Publisher Attribution

Johnston, Robert J., James J. Opaluch, Ginele Magnusson and Marisa J. Mazotta. "Who Are Resource Nonusers and What Can They Tell Us About Nonuse Values? Decomposing User and Nonuser Willingness to Pay for Coastal Wetland Restoration." Water Resources Research. 41(7):\#W07017. July 16, 2005. Available at: http://dx.doi.org/10.1029/2004WR003766

This Article is brought to you for free and open access by the Environmental and Natural Resource Economics at DigitalCommons@URI. It has been accepted for inclusion in Environmental and Natural Resource Economics Faculty Publications by an authorized administrator of DigitalCommons@URI. For more information, please contact digitalcommons-group@uri.edu.
} 


\title{
Who are resource nonusers and what can they tell us about nonuse values? Decomposing user and nonuser willingness to pay for coastal wetland restoration
}

\author{
Robert J. Johnston \\ Department of Agricultural and Resource Economics, University of Connecticut at Avery Point, Groton, Connecticut, USA
}

James J. Opaluch and Gisele Magnusson

Department of Environmental and Natural Resource Economics, University of Rhode Island, Kingston, Rhode Island, USA

Marisa J. Mazzotta

Charlestown, Rhode Island, USA

Received 26 October 2004; revised 5 April 2005; accepted 12 April 2005; published 16 July 2005.

[1] This article assesses the potential for incomplete definitions of resource use to influence estimates of nonuser willingness to pay (WTP), with an emphasis on resources for which an exhaustive set of uses may be difficult to characterize. The data are drawn from a stated preference analysis involving coastal wetland restoration. Results suggest that mechanisms used to distinguish users and nonusers of wetland services may influence estimates of nonuser WTP and that for some attributes, traditional distinctions between user and nonuser WTP may have arguable empirical justification. More broadly, results suggest that relationships among use behaviors and restoration values may be more complex than are typically assumed and point to limitations in methods frequently used to distinguish user and nonuser WTP.

Citation: Johnston, R. J., J. J. Opaluch, G. Magnusson, and M. J. Mazzotta (2005), Who are resource nonusers and what can they tell us about nonuse values? Decomposing user and nonuser willingness to pay for coastal wetland restoration, Water Resour. Res., 41, W07017, doi:10.1029/2004WR003766.

\section{Introduction}

[2] Despite concerns of economists regarding the validity of methods that decompose estimates of use and nonuse value [Cummings and Harrison, 1995], such practices remain a common part of contemporary benefit cost analysis. For example, U.S. Environmental Protection Agency (USEPA) benefit estimation conducted in support of Phase II implementation of the Clean Water Act 316b rule, addressing entrainment and impingement of fish and shellfish in cooling water intake structures, incorporates distinct analyses to estimate use and nonuse values [USEPA, 2003a]. Similar separation of use and nonuse values may be found in other policy applications of benefit cost analysis to water resources, including USEPA benefit estimates for effluent guidelines for metal products and machinery [USEPA, 2003b], guidelines for effluents in mining [USEPA, 2000b], and others.

[3] While there may be little theoretical rationale for the decomposition of use and nonuse values, the incentive for such decomposition in applied policy analysis is clear. Stated preference methods, the most widely accepted means for estimating nonuse values [Arrow et al., 1993; USEPA, 2000a], are often challenged or delayed by oversight agencies such as the federal Office of Management and Budget (OMB) [Griffiths, 2002]. Consequently, to increase the

Copyright 2005 by the American Geophysical Union. 0043-1397/05/2004WR003766 likelihood that use value estimates will survive OMB or other review, revealed preference methods are often used for the estimation of these components of nonmarket value. Stated preference methods, or associated benefit transfers, are used only for estimation of nonuse values. This common practice requires that researchers isolate nonuse values from total WTP estimates typically provided by stated preference methods, or decompose total value estimates into use and nonuse components.

[4] One of the more defensible means of distinguishing use and nonuse values in a stated preference context is to estimate nonuse values as the total willingness to pay (WTP) of nonusers [Cummings and Harrison, 1995; Johnston et al., 2003a]. A primary advantage of this approach is the general conceptual acceptance of nonuser values, even among those highly critical of use/nonuse value decomposition [Cummings and Harrison, 1995].

[5] Examples of this method of nonuse value estimation are provided by Whitehead et al. [1995], Croke et al. [1986], Olsen et al. [1991], Cronin [1982], Whitehead and Groothuis [1992], and Mitchell and Carson [1981]. Within such analyses, respondents are generally characterized as nonusers if they do not report specified uses of a resource during a defined historical period, and do not expect similar uses during a defined future period [Johnston et al., 2003a]. Although limitations of this method include the potential for bias if systematic differences exist between nonuse values of users and nonusers [Whitehead and Blomquist, 1991; Cummings and Harrison, 1995], it none- 
theless remains one of the more common means of gaining insight into the magnitude of potential nonuse values, and indeed is recommended by USEPA [2000a, p. 84] as a "more practical approach [to measuring] nonuse values."

[6] Unlike alternative means of gaining insight into the magnitude of nonuse values, the estimation of nonuser values does not require respondents to apportion their WTP into use and nonuse components, nor does it require a combination of revealed and stated preference methods [Johnston et al., 2003a]. Nonetheless, there remain unresolved issues in the literature [Freeman, 2003, p. 141] regarding "how [one defines] the use behind use values" and, conversely, how one defines the absence of use by which one might define nonusers. While certain resources may lend themselves to simple characterization of resource use, others may support myriad, often difficult-to-observe uses. In such cases, incomplete definitions of resource use may result in ambiguous definitions of nonusers. Where ambiguities occur, reported nonuser values may contain unsuspected use value components, leading to the potential for misguided assessments of true nonuser welfare and nonuse WTP.

[7] Given that practical considerations encourage analyses that decompose user and nonuser values, assessment of the mechanisms used to accomplish this task may have critical implications for applied welfare estimation. This article assesses the potential for incomplete or ambiguous definitions of resource use to influence estimates of nonuser WTP, and whether the decomposition of user and nonuser WTP is empirically tractable for primarily nonrecreational water resources such as coastal wetlands. That is, given that resources may be subject to various definitions of resource use, to what extent do researchers risk providing biased nonuser WTP estimates by relying on definitions that are potentially incomplete? Combined theoretical and empirical models are designed such that hypothesis tests may reveal, at least in a single case study involving coastal wetlands, the potential for incomplete definitions of resource use to generate misleading welfare and policy guidance. Data are drawn from "Rhode Island salt marsh restoration: A 2001 survey of Rhode Island residents" [Johnston et al. 2002].

\section{Conceptualizing User and Nonuser Willingness to Pay}

[8] For some resources, such as beaches or other sites used solely for recreation, one may easily imagine choking off or eliminating visitation in order to isolate nonuse values, a common conceptual approach to existence or nonuse values. However, for many issues of interest to researches and policymakers (e.g., habitat conservation, wetland restoration) it may be difficult to characterize the full set of direct and indirect uses through which individuals derive utility.

[9] Past studies seeking to estimate nonuser WTP for water resources have defined nonuse with differing degrees of stringency, using single or multiple indicators to identify nonusers. The tendency, however, is toward definitions that rely heavily on the absence of recreation. For example, Mitchell and Carson [1981] define a nonuser as a respondent who had not engaged in boating, fishing, or swimming within the past two years. Whitehead et al. [1995, p. 243] apply a more stringent definition, identifying nonusers as those respondents who had not engaged in "fishing, swimming, boating, or some other activity" in specified water bodies, nor had "heard or read about the resources, uses, and problems" of the water bodies in question. Like Mitchell and Carson [1981], Cronin [1982] defines nonusers based on a lack of participation in specific recreational activities (swimming, boating, fishing, hiking, camping, or picnicking), but expands the definition of users to encompass activities of other household members, and in water bodies other than the particular river in question.

[10] Unlike primarily recreational resources, however, coastal wetlands may provide a wide range of use values, including values related to recreational activities (e.g., fishing, shellfishing, birding), nonrecreational aesthetics (e.g., viewing a wetland during a daily commute), and wetland services used off site (e.g., nutrient processing, erosion control) [Johnston et al., 2002]. In such cases, identification of nonusers based solely on an absence of recreational use will likely misspecify the set of true nonusers. Even in cases purportedly characterized by straightforward definitions of resource use, unexpected sources of use values may be present, such as values derived from indirect, vicarious or off-site uses of the resource in question [Randall and Stoll, 1983; Whitehead et al., 1995]. For example, a recreational angler might realize indirect use values from fish spawning services provided by distant coastal wetlands, even if he or she never visits these wetlands.

[11] Such issues have led some academics to suggest discarding common distinctions of use and nonuse (and by extension, user and nonuser) values in favor of classifications based solely on relationships to observable or market behavior [e.g., Mäler et al., 1994]. Others have argued that such distinctions are only useful if they assist in the primary goal of total value estimation [Freeman, 2003]. However, as noted above, methods that decompose user and nonuser values are commonly encountered in applied benefit cost analyses. Hence assessments of the validity and implications of these methods may have significant consequences for the application of benefit cost analysis to water resources.

\section{A Random Utility Model of Wetland Restoration}

[12] The literature provides various formulations of the utility theoretic basis for nonuse values [e.g., Carson et al., 1999; Freeman, 2003; McConnell, 1983]. Here the emphasis is not on use versus nonuse values, but rather on user versus nonuser values. Nonetheless, we follow in the tradition of conceptual models such as that of Carson et al. [1999, pp. 102-103] who distinguish users and nonusers based on interactions between observable consumption activities and nonmarket environmental goods. Conceptually, users are defined as individuals who participate in at least one of a set of observable activities through which utility may be derived from a natural resource. Nonusers are defined as individuals who do not engage in such activities.

[13] Following standard random utility model conventions [McConnell, 1990; Hanemann, 1984], utility is presumed to be composed of systematic and stochastic components. An individual's utility is assumed to be a function of both wetland resource-related behaviors $\mathbf{X}$ and 
wetland quality attributes $\mathbf{Q}$, such that utility from a wetland restoration plan $i$ may be specified

$$
U\left(\mathbf{X}_{\mathbf{i}}, \mathbf{Q}_{\mathbf{i}}, y-C_{i}\right)=v\left(\mathbf{X}_{\mathbf{i}}, \mathbf{Q}_{\mathbf{i}}, y-C_{i}\right)+\varepsilon_{i} .
$$

Here, $U(\cdot)$ represents total utility, $v(\cdot)$ represents the systematic or potentially observable component of utility, and $\varepsilon_{i}$ represents the stochastic or unobservable component. The vector $\mathbf{Q}_{\mathbf{i}}=\left[q_{i 1}, q_{i 2}, \ldots q_{i J}\right]$ characterizes $J$ wetland quality attributes resulting from plan $i$. The vector $\mathbf{X}_{\mathbf{i}}=\left[x_{i 1}\right.$, $\left.x_{i 2}, \ldots, x_{i N}\right]$ quantifies $N$ observable wetland use activities. For example, $x_{i 1}>0$ might indicate nonzero participation in activity $n=1$, such as a specified recreational use of wetland resources. Although some elements of $\mathbf{X}_{\mathbf{i}}$ may include observable market behaviors, others may be behaviors with no observable price (e.g., viewing a wetland during a daily commute). The variable $y$ represents household income, and the unavoidable household cost of plan $i$ is given by $C_{i}$.

[14] We assume that for nonusers $\mathbf{X}_{\mathbf{i}}=\mathbf{0}$, such that $U\left(\mathbf{X}_{\mathbf{i}}\right.$, $\left.\mathbf{Q}_{\mathbf{i}}, y-C_{i}\right)=U\left(\mathbf{Q}_{\mathrm{i}}, y-C_{i}\right)$. Here, all utility related to wetland attributes is derived directly from $\mathbf{Q}_{\mathbf{i}}$. For users, at least some elements of $\mathbf{X}_{\mathbf{i}}$ are nonzero. Hence only users derive utility from $\mathbf{Q}_{\mathbf{i}}$ through participation in $\mathbf{X}_{\mathbf{i}}$. However, users may also derive nonuse values from changes in $\mathbf{Q}_{\mathbf{i}}$ directly, such that $\partial U(\cdot) /\left.\partial \mathbf{Q}_{\mathbf{i}}\right|_{\mathbf{X}=0} \geq 0$. That is, we do not impose assumptions such as weak complementarity. The price vector for $\mathbf{X}_{\mathbf{i}}$ is suppressed for convenience, as market prices are assumed constant, and some activities in $\mathbf{X}_{\mathbf{i}}$ may have no observable price. While a variable price vector may have critical implications in a revealed preference context (e.g., when alluding to weak complementarity), it plays no active role in the random utility model presented here.

[15] It is possible that participation in various elements of activity vector $\mathbf{X}_{\mathbf{i}}$ might vary across different types of restoration plans $i$, such that an individual's user or nonuser status is endogenous. This possibility notwithstanding, the stated preference literature typically defines nonusers based on the absence of current use [e.g., Mitchell and Carson, 1981; Whitehead et al., 1995], under the assumption that use behaviors are approximately constant across survey scenarios. We follow the same tradition. This approach allows the model to be estimated with existing data. It is also supported by focus group results that, in the present case, provide little evidence that restoration activities described in survey scenarios would alter respondents' user or nonuser status with regard to coastal wetlands. Although the present analysis does not address the possibility of changes in user or nonuser status among respondents, the potential endogeneity of this status represents yet another possible issue faced in the identification of nonuser values.

[16] Given the above specification, we assume that the respondent considers two wetland restoration plans $i$, where $i=(A, B)$ identifies plans $\mathrm{A}$ and $\mathrm{B}$. Plan $\mathrm{A}$ is characterized by wetland quality attributes $\mathbf{Q}_{\mathbf{A}}$ and $\operatorname{cost} C_{A}$, whereas plan $\mathrm{B}$ is characterized by quality attributes $\mathbf{Q}_{\mathbf{B}}$ and $\operatorname{cost} C_{B}$. The respondent may choose plan $\mathrm{A}$, plan $\mathrm{B}$, or may reject both plans (i.e., choose neither plan, $i=\mathrm{N}$ ). A choice of neither plan would result in baseline (i.e., nonrestored) wetland quality $\mathbf{Q}_{\mathbf{N}}$ and zero household cost. The model assumes that the respondent assesses the utility that would result from available choice options $(i=A, B, N)$ and chooses the option that offers the greatest utility. For example, given (1), the respondent will choose plan $\mathrm{A}$ if

$$
U\left(\mathbf{X}_{\mathbf{A}}, \mathbf{Q}_{\mathbf{A}}, y-C_{A}\right) \geq U\left(\mathbf{X}_{\mathbf{k}}, \mathbf{Q}_{\mathbf{k}}, y-C_{k}\right) \text { for } k=B, N,
$$

such that

$$
v\left(\mathbf{X}_{\mathbf{A}}, \mathbf{Q}_{\mathbf{A}}, y-C_{A}\right)+\varepsilon_{A} \geq v\left(\mathbf{X}_{\mathbf{k}}, \mathbf{Q}_{\mathbf{k}}, y-C_{k}\right)+\varepsilon_{k} .
$$

If the $\varepsilon_{i}$ are assumed independently and identically drawn from a type I extreme value distribution, the model may be estimated as a conditional logit model, as detailed by Maddala [1983] and Greene [2003].

\section{Defining User and Nonuser Values}

[17] The standard model (1)-(3) may be easily customized to allow different utility specifications for different groups, and different definitions of users and nonusers. Ideally, one would define nonusers as respondents for whom $\mathbf{X}_{\mathbf{i}}=\mathbf{0}$, and users as those for whom at least one element of $\mathbf{X}_{\mathbf{i}}$ is nonzero. However, if some elements of $\mathbf{X}_{\mathbf{i}}$ are difficult to observe or characterize, researchers might also generate incomplete definitions of resource nonuse based on $x_{i}=0$ for an incomplete subset $\bar{n}<N$ set of indicator activities. A researcher might, for example, specify nonusers based on the incomplete criteria $\mathbf{X}_{\mathbf{i}}=[0$, $\left.x_{i 2}, \ldots, x_{i N}\right]$ rather than $\mathbf{X}_{\mathbf{i}}=\mathbf{0}$. Here, despite the designation of a respondent as a nonuser, utility is derived from either direct or indirect resource uses. Accordingly, WTP estimates derived from (1)-(3) [cf. Hanemann, 1984] will incorporate unanticipated use value components.

[18] As an example, consider that researchers may be able to accurately identify individuals who use coastal wetlands for on-site recreational fishing. However, it may be more difficult to identify users of indirect wetland services, such as offshore anglers (perhaps hundreds of miles distant) who fish for migratory species that rely upon coastal wetlands as a nursery during juvenile life stages. Moreover, while some off-site users may know that they are users of the natural resource in question, others may have little or no knowledge that they indirectly use specific resource services. Such lack of knowledge may further complicate the search for unambiguous definitions of resource users and nonusers.

[19] In still other cases, there may be instances of measurable WTP that one might intuitively classify as use values, but are associated with no readily observable behavior. For example, one might classify WTP for mosquito control in restoration projects as a use value, as it derives from a desire to avoid mosquito nuisance and the potential for associated diseases. However, this apparent use value may not be associated with any observable element of activity vector $\mathbf{X}_{\mathbf{i}}$. Accordingly, even nonusers defined according to the apparently complete criteria $\mathbf{X}_{\mathbf{i}}=\mathbf{0}$ may nonetheless derive values that some would classify as use values.

[20] The above arguments might seem to provide a discouraging message with regard to researchers' ability to distinguish nonuser WTP as a source of potential insight into nonuse values. However, the empirical severity of the problem may depend on the ease of defining resource use in specific cases, and on whether incomplete definitions of use 
result in significant differences in estimated WTP. In some cases, incomplete definitions of resource use may lead to significant differences in WTP, leading to the potential for substantial biases if the full range of resource uses is difficult to characterize. In other cases, estimates of nonuser WTP might be robust to changes in specific definitions of resource use, thereby providing researchers with a practical approximation to nonuser values even given potentially incomplete definitions. The principal empirical question, then, is whether estimated nonuser WTP is sensitive to changes in mechanisms used to define nonusers, and implications of these results for welfare estimation.

\section{An Empirical Application}

[21] To assess these empirical questions we estimate a model of user and nonuser stated preferences for coastal wetland restoration plans. We estimate a random utility model allowing calculation of user and nonuser WTP for a variety of different coastal wetland attributes; WTP is estimated based on choice experiment data. User and nonuser WTP are assessed under differing definitions of resource nonuse, determined by a set of nonuse indicators. The model allows a systematic assessment of the impacts of increasingly stringent (or simply different) indicators of resource nonuse on estimated nonuser WTP.

\subsection{Choice Experiment Data}

[22] The data are drawn from "Rhode Island salt marsh restoration: A 2001 survey of Rhode Island residents" [Johnston et al., 2002]. The survey was designed to identify public values for changes in salt marsh functions provided by restoration actions. Survey development required over sixteen months and involved extensive background research, interviews with experts in marsh ecology and restoration, and sixteen focus groups with over 100 Rhode Island residents [Johnston et al., 2002]. Numerous pretests, including verbal protocols [Schkade and Payne, 1994], were also conducted to ensure that the survey language and format could be easily understood by respondents, and that respondents shared interpretations of survey scenarios [Johnston et al., 2002]. Pretests were incorporated into focus groups, and were also conducted through individual in-person interviews with Rhode Island residents. Although the exact number of individual interview pretests was not recorded, we estimate that at least 50 were conducted between October 2000 and September 2001, in addition to pretests conducted in organized focus groups.

[23] Focus groups and pretests led to a self administered, in-person survey that combined a printed survey booklet with an 8-min introductory video presentation. This presentation introduced respondents to information regarding salt marshes and restoration; reminded respondents of tradeoffs involved in salt marsh restoration; reminded respondents of their budget constraint and the implications of choosing to direct funds to restoration programs; emphasized the importance of respondents' choices; and provided survey instructions. The script and graphics of the presentation were pretested extensively, and iteratively revised along with the survey booklet.

[24] Stated preference questions were designed as choice experiments [Adamowicz et al., 1998]. Each survey booklet presented the respondent with four sets of discrete choices, each involving two alternative, hypothetical multiattribute restoration plans that would take place in Narragansett Bay. Respondents were instructed, in both video and text, to consider each pair independent of previous choices. Fractional factorial design was used to construct a range of survey questions with an orthogonal array of attribute levels, resulting in 80 choice questions divided among 20 unique booklets. Attributes distinguishing plans were selected based on background research, expert interviews, and focus groups, and characterized such features as bird, fish, and shellfish habitat; wetland size; mosquito control, public access facilities, and annual household cost (Table 1). On the basis of these attributes, respondents chose one of the two plans, or chose "neither plan."

[25] Aside from stated preference questions, the survey elicited a variety of information regarding respondents' use of and proximity to Rhode Island salt marshes. For example, respondents were asked (1) whether they ever used salt marshes for canoeing/kayaking, hiking/walking, bird watching, shell fishing/crabbing, fishing, swimming, hunting, or other outdoor activities, (2) the frequency with which they drove by or viewed Rhode Island salt marshes, and (3) whether they lived within sight of a salt marsh. Responses to these questions may be used to derive a variety of definitions for a resource nonuser. For example, one may distinguish between recreational nonusers and those who in addition neither (regularly) drive by nor live within sight of Rhode Island salt marshes, a more complete definition of nonuse. Model variables derived from these questions are summarized in Table 1.

[26] The survey was conducted from September through December 2001. Respondents were intercepted in person at survey locations including Rhode Island Department of Motor Vehicle (DMV) offices, public libraries, and other public sites. Survey locations were selected from hightraffic public sites, with a goal of providing interviewer access to a broad representation of Rhode Island residents, including respondents from a wide range of socioeconomic groups. Rhode Island DMV offices were also considered ideal, as extended waiting times were common at these offices, leaving large amounts of time for individuals to complete the survey. In total, interviewers collected 661 surveys, providing responses to 2341 contingent choice questions (89\% of the potential 2644).

\subsection{Econometric Model and Analysis}

[27] To allow for a variety of potential definitions of nonuse within the empirical model, we introduce two binary variables characterizing the absence of different dimensions of resource use. The first, nonrec, identifies individuals who do not participate in a comprehensive list of recreational uses of salt water wetlands (nonrec $=1$ indicates a recreational nonuser). The second, nonproximate, identifies individuals who do not drive by, view, or live within sight of a salt water wetland (Table 1). Combinations of these two variables allow for various definitions of nonusers. For example, one might define a nonuser based solely on nonparticipation in recreational uses of wetland resources (nonrec $=1$ ), following similar definitions applied elsewhere [e.g., Mitchell and Carson, 1981; Cronin, 1982]. In contrast, one might apply a more restrictive definition, 
Table 1. Model Variables: Definitions and Summary Statistics

\begin{tabular}{|c|c|c|}
\hline Variable Name & Description & Mean (SD) \\
\hline neither & $\begin{array}{l}\text { neither }=1 \text { identifies "neither plan" choice option (alternative } \\
\text { specific constant) }\end{array}$ & $0.3333(0.4714)$ \\
\hline environ & $\begin{array}{l}\text { binary variable }(0,1) \text { indicating membership of respondent in } \\
\text { environmental organizations }\end{array}$ & $0.1890(0.3916)$ \\
\hline taxgroup & $\begin{array}{l}\text { binary variable }(0,1) \text { indicating membership of respondent in } \\
\text { taxpayer associations }\end{array}$ & $0.0233(0.1510)$ \\
\hline lo_income & $\begin{array}{l}\text { binary variable }(0,1) \text { identifying respondents with household } \\
\text { income less than } \$ 35,000 / \mathrm{yr}\end{array}$ & $0.2428(0.4288)$ \\
\hline hi_educate & $\begin{array}{l}\text { binary variable }(0,1) \text { identifying respondents with greater than } \\
\text { a } 4 \text {-year college degree }\end{array}$ & $0.1830(0.3867)$ \\
\hline age & age of respondent, in years & $39.1244(15.0496)$ \\
\hline bird & ecological improvement to bird populations $(0-10 \mathrm{scale})^{\mathrm{a}}$ & $2.7664(2.6048)$ \\
\hline fish & ecological improvement to fish populations $(0-10 \text { scale })^{\mathrm{a}}$ & $2.9063(2.6519)$ \\
\hline shellfish & ecological improvement to shellfish populations $(0-10 \text { scale })^{\mathrm{a}}$ & $2.9151(2.6543)$ \\
\hline mosquito & improved potential to control mosquito nuisance $(0-10 \text { scale })^{\mathrm{b}}$ & $2.9098(2.6512)$ \\
\hline acres & size of restored salt marsh, in acres & $4.8961(4.3995)$ \\
\hline platform & $\begin{array}{l}\text { binary }(0,1) \text { variable indicating that restoration provides } \\
\text { "viewing platforms" }\end{array}$ & $0.2267(0.4187)$ \\
\hline plat_trail & $\begin{array}{l}\text { binary }(0,1) \text { variable indicating that restoration provides both } \\
\text { "viewing platforms" and "trails" }\end{array}$ & $0.2219(0.4155)$ \\
\hline tax_cost & annual cost of plan to the household (increase in state taxes) & $62.9691(70.6690)$ \\
\hline nonrec & $\begin{array}{l}\text { binary }(0,1) \text { variable identifying respondents who do not } \\
\text { engage regularly (at least } 3-4 \text { times per year) in any of the } \\
\text { following activities in or around salt marshes: canoeing/ } \\
\text { kayaking, hiking/walking, bird-watching, } \\
\text { shellfishing/crabbing, recreational fishing, swimming, } \\
\text { hunting, or other outdoor activities }\end{array}$ & $0.3187(0.4660)$ \\
\hline nonproximate & $\begin{array}{l}\text { binary }(0,1) \text { variable identifying respondents who "drive by or } \\
\text { otherwise view... salt marshes" less than once per month } \\
\text { and who do not "live within sight of a salt marsh" }\end{array}$ & $0.4363(0.4959)$ \\
\hline $\begin{array}{l}{ }^{\mathrm{a}} \text { All ecologic } \\
\text { respondents as } \\
\text { potential salt } \mathrm{m} \\
{ }^{\mathrm{b}} \text { The potenti } \\
\text { respondents as }\end{array}$ & $\begin{array}{l}\text { ent variables (bird, fish, shellfish) were described on a }(0-10) \text { s } \\
\text { al improvement" to statewide populations "as judged by wetlat } \\
\text { on projects in Rhode Island." } \\
\text { mosquito nuisance (mosquito) was described on a }(0-10) \text { sca } \\
\text { to control mosquito nuisance. . . as judged by wetland experts, c } \\
\text { Rhode Island." }\end{array}$ & $\begin{array}{l}\text { le was described to } \\
\text { mpared to all other } \\
\text { was described to } \\
\text { other potential salt }\end{array}$ \\
\hline
\end{tabular}

characterizing a nonuser as a respondent for whom both nonrec $=1$ and nonproximate $=1$.

[28] As respondents considered three choice options (i.e., plan $\mathrm{A}$, plan $\mathrm{B}$, neither) for each question, the model is estimated as a conditional logit model, where the dependent variable identifies the choice made in response to each question. For example, if a respondent were to choose plan $\mathrm{A}$ in response to a choice question, the binary dependent variable would be assigned a value of 1 for plan $i=\mathrm{A}$ and 0 for plans $i=(\mathrm{B}, \mathrm{N})$. To allow utility to vary across groups, the utility specification incorporates systematically varying slopes according to the two definitions of a resource nonuser (nonrec, nonproximate). That is, the econometric model is characterized by the utility specification

$$
\begin{aligned}
v(\cdot)= & \boldsymbol{\beta}(\mathbf{Q})+\boldsymbol{\lambda}_{1}(\mathbf{Q})(\text { nonrec })+\boldsymbol{\lambda}_{2}(\mathbf{Q})(\text { nonproximate }) \\
& +\boldsymbol{\gamma}(\text { tax_cost })+\psi_{1}(\text { tax_cost })(\text { nonrec }) \\
& +\psi_{2}(\text { tax_cost })(\text { nonproximate })
\end{aligned}
$$

where $\mathbf{Q}$ represents the vector of wetland attributes provided by a restoration plan, tax_cost represents unavoidable household taxes required to implement the plan, and conforming parameter estimates are given by $\beta, \lambda_{1}, \lambda_{2}, \gamma$, $\psi_{1}$, and $\psi_{2}$. Given (4), marginal utilities of $\mathbf{Q}$ for respondents characterized by nonrec $=1$ and nonproximate $=0$ are given by $\left(\boldsymbol{\beta}+\lambda_{1}\right)$; marginal utilities for respondents characterized by nonrec $=1$ and nonproximate $=1$ are given by $\left(\boldsymbol{\beta}+\boldsymbol{\lambda}_{1}+\boldsymbol{\lambda}_{\mathbf{2}}\right)$.

[29] As the final data are composed of four responses per survey (i.e., panel data), there is a possibility of correlated errors across responses. That is, responses provided by individual respondents may be correlated even though responses across different respondents are considered iid. A standard approach to such potential correlation is the random parameters discrete choice model [Greene, 2003; McFadden and Train, 2000; Train, 1998]. Although the most flexible model specifications allow for a random distribution of the entire parameter vector, in practice one may experience difficulties in convergence when large numbers of random parameters are incorporated [e.g., Layton, 2000; Johnston et al., 2003b]. Here, we estimate (4) assuming that the coefficient vector $\boldsymbol{\beta}$ (associated with linear salt marsh attributes) is normally distributed across respondents. The remaining parameters $\lambda_{1}, \lambda_{2}, \gamma, \psi_{1}$, and $\psi_{2}$ (interactions and household cost) are assumed to be nonrandom. This common practice avoids ambiguities associated with the calculation of WTP as the ratio of two distributions (C. M. Anderson et al., A stated preference study of parking choices among tourists in Newport, Rhode Island, staff paper, Department of Environmental and Natural Resource Economics, University of Rhode Island, Kingston, 2004, p. 21). The model is estimated using maximum likelihood for mixed conditional logit (or random 
Table 2. Random Parameters Logit (RPL) Results ${ }^{\mathrm{a}}$

\begin{tabular}{|c|c|c|c|c|}
\hline Variable & Parameter Vector & Estimate & Standard Error & Probability $|\mathrm{Z}|>\mathrm{z}$ \\
\hline neither ${ }^{\mathrm{b}}$ & $\beta$ & 1.6621 & 0.7271 & 0.0223 \\
\hline neither $\times$ taxgroup & $\beta$ & 1.0946 & 1.1739 & 0.3511 \\
\hline neither $\times$ lo income & $\beta$ & 0.1439 & 0.4358 & 0.7412 \\
\hline neither $\times$ hi_educate & $\beta$ & 0.3699 & 0.5738 & 0.5192 \\
\hline neither $\times$ age & $\beta$ & -0.0235 & 0.0144 & 0.1025 \\
\hline neither $\times$ environ & $\beta$ & -1.3860 & 0.6179 & 0.0249 \\
\hline bird $^{\mathrm{b}}$ & $\beta$ & 0.2136 & 0.0418 & 0.0001 \\
\hline$f i s h^{\mathrm{b}}$ & $\beta$ & 0.2283 & 0.0394 & 0.0001 \\
\hline shellfish $^{\mathrm{b}}$ & $\beta$ & 0.2637 & 0.0434 & 0.0001 \\
\hline mosquito ${ }^{\mathrm{b}}$ & $\beta$ & 0.2122 & 0.0371 & 0.0001 \\
\hline platform $^{\mathrm{b}}$ & $\beta$ & 0.4497 & 0.1869 & 0.0161 \\
\hline plat trail $^{\mathrm{b}}$ & $\beta$ & 0.8180 & 0.1917 & 0.0001 \\
\hline acres $^{\mathrm{b}}$ & $\beta$ & 0.0670 & 0.0236 & 0.0045 \\
\hline tax_cost & $\gamma$ & -0.0098 & 0.0009 & 0.0001 \\
\hline neither $\times$ nonrec & $\lambda_{1}$ & 0.2588 & 0.7672 & 0.7358 \\
\hline bird $\times$ nonrec & $\lambda_{1}$ & -0.0662 & 0.0651 & 0.3088 \\
\hline fish $\times$ nonrec & $\lambda_{1}$ & 0.0259 & 0.0589 & 0.6593 \\
\hline shellfish $\times$ nonrec & $\lambda_{1}$ & 0.0781 & 0.0671 & 0.2438 \\
\hline mosquito $\times$ nonrec & $\lambda_{1}$ & 0.0804 & 0.0638 & 0.2081 \\
\hline platform $\times$ nonrec & $\lambda_{1}$ & -0.2400 & 0.2973 & 0.4195 \\
\hline plat_trail $\times$ nonrec & $\lambda_{1}$ & -0.0752 & 0.3289 & 0.8193 \\
\hline acres $\times$ nonrec & $\lambda_{1}$ & -0.0512 & 0.0383 & 0.1806 \\
\hline tax_cost $\times$ nonrec & $\psi_{1}$ & -0.0033 & 0.0017 & 0.0536 \\
\hline neither $\times$ nonproximate & $\lambda_{2}$ & -0.4307 & 0.7153 & 0.5470 \\
\hline bird $\times$ nonproximate & $\lambda_{2}$ & 0.8491 & 0.0627 & 0.1759 \\
\hline fish $\times$ nonproximate & $\lambda_{2}$ & -0.1072 & 0.0568 & 0.0590 \\
\hline shellfish $\times$ nonproximate & $\lambda_{2}$ & -0.0733 & 0.0631 & 0.2451 \\
\hline mosquito $\times$ nonproximate & $\lambda_{2}$ & 0.0139 & 0.0585 & 0.8120 \\
\hline platform $\times$ nonproximate & $\lambda_{2}$ & -0.0641 & 0.2640 & 0.8083 \\
\hline plat_trail $\times$ nonproximate & $\lambda_{2}$ & -0.2773 & 0.2931 & 0.3442 \\
\hline acres $\times$ nonproximate & $\lambda_{2}$ & 0.0882 & 0.0373 & 0.0182 \\
\hline tax_cost $\times$ nonproximate & $\psi_{2}$ & -0.0009 & 0.0016 & 0.5692 \\
\hline Log likelihood & & -1745.38 & & \\
\hline$-2 L n L \chi^{2}$ & & 1560.66 & $\mathrm{df}=68^{\mathrm{a}}$ & 0.0001 \\
\hline $\begin{array}{l}\chi^{2} \text { for RPL versus fixed } \\
\text { parameters logit }\end{array}$ & & 390.78 & $\mathrm{df}=36$ & 0.0001 \\
\hline$\underset{N}{\chi^{2}}$ for $H_{0}: \lambda_{1}=\lambda_{2}=\psi_{1}=\psi_{2}=0$ & & $\begin{array}{l}31.69 \\
2306^{\mathrm{c}}\end{array}$ & $\mathrm{df}=18$ & 0.0230 \\
\hline
\end{tabular}

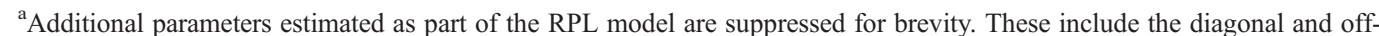
diagonal elements of the Cholesky matrix for random parameters and the associated standard deviations of random parameter distributions. In total, 68 parameters are estimated; 32 are illustrated.

${ }^{\mathrm{b}}$ Random parameter (others are considered fixed).

${ }^{\mathrm{c}}$ Thirty-five observations of the original 2341 were deleted due to missing values.

parameters logit (RPL)) with Halton draws applied in the log likelihood simulation [Greene, 2002].

\section{Results and Discussion}

[30] Model results are presented in Table 2. The model is significant at $\mathrm{p}<0.0001\left(\chi^{2}=1560.66, \mathrm{df}=68\right)$. A likelihood ratio test of the RPL model versus a conditional logit model in which all parameters are fixed rejects the null hypothesis of a fixed $\beta$ vector at $\mathrm{p}<0.01\left(\chi^{2}=390.78, \mathrm{df}=\right.$ 36). A likelihood ratio test of the unrestricted model (Table 2) compared to a restricted model in which $\boldsymbol{\lambda}_{\mathbf{1}}=\boldsymbol{\lambda}_{\mathbf{2}}=\psi_{1}=\psi_{2}=$ 0 rejects the null hypothesis of zero joint influence at $\mathrm{p}<$ $0.03\left(\chi^{2}=31.69, \mathrm{df}=18\right)$, indicating that the indicators nonrec and nonproximate are jointly associated with statistically significant changes in $v(\cdot)$. That is, indicators of resource nonuse are jointly associated with changes in marginal utility. All parameter estimates associated with noninteracted resource quality attributes $(\boldsymbol{\beta})$ are statistically significant. Signs of parameter estimates correspond with expectations derived from focus groups and the wetlands valuation literature [Boyer and Polasky, 2004]. For example, respondents favor plans that restore larger marshes; improve bird, fish, and shellfish habitat; improve mosquito control; provide public access; and have lower cost.

[31] Parameter estimates in Table 2 allow one to assess the statistical significance of changes in marginal utilities associated with the nonuse indicators nonrec and nonproximate. However, the presence of statistically significant changes in marginal utilities does not necessarily imply changes (statistically significant or otherwise) in associated WTP. To assess differences in nonuser WTP associated with different indicators of nonuse, we compare WTP for the cases in which (1) nonrec $=0$ and nonproximate $=0$; (2) nonrec $=1$ and nonproximate $=0$; and (3) nonrec $=1$ and nonproximate $=1$. To simplify discussion, we denote those for whom nonrec $=0$ and nonproximate $=0$ as "users". Those for whom nonrec $=1$ and nonproximate $=$ 0 are denoted "recreational nonusers." and those for whom nonrec $=1$ and nonproximate $=1$ are denoted "complete nonusers." This naming convention does not imply that we assume that nonrec and nonproximate capture all possible 
Table 3. Marginal Willingness to Pay (WTP) for Wetland Attributes

\begin{tabular}{lccc}
\hline Variable & $\begin{array}{c}\text { WTP of Users } \\
\text { (Standard Error) }\end{array}$ & $\begin{array}{c}\text { WTP of Recreational } \\
\text { Nonusers } \\
\text { (Standard Error) }\end{array}$ & $\begin{array}{c}\text { WTP of Complete } \\
\text { Nonusers } \\
\text { (Standard Error) }^{\mathrm{a}, \mathrm{d}}\end{array}$ \\
\hline bird & $21.91(4.34)$ & $11.29(5.14)$ & $16.66(4.20)$ \\
fish & $23.41(4.43)$ & $19.48(5.04)$ & $10.54(3.80)$ \\
shellfish & $27.04(4.92)$ & $26.20(6.18)$ & $19.25(4.53)$ \\
mosquito & $21.76(3.98)$ & $22.42(5.15)$ & $21.97(3.99)$ \\
platform & $46.12(19.33)$ & $16.07(22.96)$ & $10.44(18.95)$ \\
plat_trail & $83.90(20.94)$ & $56.94(26.01)$ & $33.38(19.63)$ \\
acres & $6.87(2.45)$ & $1.21(2.79)$ & $7.45(2.47)$ \\
\hline
\end{tabular}

${ }^{\mathrm{a}}$ Standard errors are calculated following Greene [2003, p. 487].

${ }^{\mathrm{b}}$ Group is defined by nonrec $=0$, nonproximate $=0$.

${ }^{\mathrm{c}} \mathrm{Group}$ is defined by nonrec $=1$, nonproximate $=0$.

${ }^{\mathrm{d}}$ Group is defined by nonrec $=1$, nonproximate $=1$.

uses through which one may gain welfare from coastal wetlands. Rather, we only argue that the combination nonrec $=1$ and nonproximate $=1$ characterizes a more complete definition of nonuser, compared to nonrec $=1$ and nonproximate $=0$.

[32] Marginal willingness to pay is calculated following Hanemann [1984] as the ratio of the marginal utility associated with wetland attributes (e.g., bird, fish, acres) and the marginal utility of program cost $(\operatorname{tax} \cos t)$. Marginal utilities are given by parameter estimates $\bar{\beta}, \lambda_{1}, \lambda_{2}, \gamma$, $\psi_{1}$, and $\psi_{2}$. For example, the vector of mean WTP values for a representative respondent for whom nonrec $=0$ and nonproximate $=0$ is given by $\beta / \gamma$. (While the RPL model estimates a distribution for each parameter estimate in $\beta$, WTP is calculated only for the mean of this distribution.) The vector of WTP values for a representative respondent for whom nonrec $=1$ and nonproximate $=1$ is given by $(\boldsymbol{\beta}+$ $\left.\lambda_{1}+\lambda_{2}\right) /\left(\gamma+\psi_{1}+\psi_{2}\right)$. Table 3 illustrates estimated WTP for each of the three cases noted above. Table 4 illustrates differences in WTP across the three cases, together with $\mathrm{p}$ values for the null hypothesis of zero difference in WTP. Hypotheses tests are conducted using nonlinear Wald tests [Greene, 2003].

[33] For five of seven attributes considered, WTP point estimates for wetland users (nonrec $=0$; nonproximate $=0$ ) exceed those of both nonuser groups (Table 3 ). Moreover, for the majority of attributes, WTP of recreational nonusers exceeds that of complete nonusers, suggesting that increased scope of use is associated with increased marginal WTP. For example, WTP point estimates for increases in fish habitat (fish), shellfish habitat (shellfish) and wetland access facilities (platform, plat_trail) decline as one successively reduces the scope of use (Table 3 ).

[34] These intuitive differences in WTP point estimates notwithstanding, the majority are not statistically significant (Table 4). For three of seven attributes (shellfish, mosquito, platform) we fail to reject the null hypothesis of zero WTP difference across groups in all cases (at $p=0.10$ ). Two of seven attributes (bird, acres) are characterized by a significant and positive WTP difference $(\mathrm{p}<0.10)$ between users and recreational nonusers, but a nonsignificant WTP difference between users and complete nonusers. The remaining two attributes (fish, plat_trail) reveal significant and positive WTP differences between users and complete nonusers, but fail to identify a significant difference between users and recreational users. Taken together, of 21 total WTP differences tested in Table 4, only six are statistically significant at $\mathrm{p}<0.10$.

[35] Model results make clear that while the expected general pattern of user values exceeding nonuser values applies to many wetland attributes (Table 3), the set of attributes for which statistically significant WTP differences (between users and nonusers) may be established is relatively small (Table 4). In addition, estimated differences

Table 4. WTP Differences Associated With Nonuse Indicators ${ }^{\mathrm{a}}$

\begin{tabular}{lccc}
\hline & WTP & & WTP \\
& Users - Recreational & WTP & Recreational \\
Nonusers & Users - Complete & Nonusers \\
Variable & (Standard Error) & (Standard Error) & Nonusers \\
bird & $10.61^{\mathrm{b}}(5.61)$ & $5.26(6.41)$ & $-5.36(4.82)$ \\
fish & $3.93(5.55)$ & $12.87^{\mathrm{c}}(6.26)$ & $8.94^{\mathrm{b}}(4.64)$ \\
shellfish & $0.84(6.50)$ & $7.79(7.21)$ & $6.95(5.50)$ \\
mosquito & $-0.66(5.33)$ & $-0.21(5.96)$ & $0.45(4.69)$ \\
platform & $30.05(24.62)$ & $35.68(29.04)$ & $5.63(19.61)$ \\
plat_trail & $26.97(27.36)$ & $50.53^{\mathrm{b}}(30.01)$ & $23.56(22.28)$ \\
acres & $5.66^{\mathrm{b}}(3.23)$ & $-0.58(3.79)$ & $-6.25^{\mathrm{c}}(2.83)$ \\
\hline
\end{tabular}

${ }^{\mathrm{a}} \mathrm{WTP}$ of users is defined by nonrec $=0$, nonproximate $=0$. WTP of recreational nonusers is defined by nonrec $=1$, nonproximate $=0$. WTP of complete nonusers is defined by nonrec $=1$, nonproximate $=1$. The $\mathrm{p}$ values are based on asymptotic Wald tests [Greene, 2003].

${ }^{\mathrm{b}}$ Here $\mathrm{p}<0.10$.

${ }^{\mathrm{c}}$ Here $\mathrm{p}<0.05$. 
between user and nonuser WTP depend on the set of indicators used to define nonusers.

[36] There are a variety of potential explanations for the difficulty in establishing statistically significant differences between user and nonuser WTP. Perhaps the most obvious is that for certain attributes and/or uses, use values may be small, such that the underlying WTP of users and nonusers is similar. A second potential explanation is that if nonuse values of nonusers exceed nonuse values of users, then the magnitude of total user and nonuser WTP might be similar, even though use values are positive.

[37] A third potential explanation is that WTP variance within each group (users; nonusers) might be sufficiently large to statistically overshadow mean WTP difference between groups. For example, even though WTP for viewing platforms (platform) among users $(\$ 46.12)$ exceeds that of complete nonusers ( $\$ 10.44$ ) by $342 \%$ (Table 3), the substantial variance associated with these WTP estimates prevents one from rejecting the null hypothesis of their equality. A large variance in the value of viewing platforms by users might result, for example, if hikers in wetlands have a positive WTP for viewing platforms, while recreational kayakers prefer an absence of platforms. In such cases, even a substantial difference in the mean WTP for users versus nonusers might not be statistically significant at standard levels.

[38] Such explanations notwithstanding, model results point to the operational difficulty in establishing clear, unambiguous empirical distinctions between user and nonuser values for wetland restoration attributes. The sensitivity of user/nonuser WTP to applied definitions of resource use further suggests that decompositions of use and nonuse value may be subject to a certain degree of arbitrariness. For example, for four of seven attributes (bird, fish, plat trail, acres) considered here, conclusions regarding the statistical significance of differences between user and nonuser WTP change as a function of the indicators used to define nonuse (Table 4).

[39] Model results also point to instances in which the use(s) underlying some types of user values may be difficult to observe or define, leading to questions regarding the empirical rationale for decomposing user and nonuser WTP. The problem is exemplified here by results associated with mosquito control in wetland restoration. While intuition suggests that WTP for mosquito control comprises an element of use value (i.e., a desire to avoid mosquito bites and associated diseases), marginal values for mosquito control (mosquito) are independent of wetland use as measured here (Tables 3 and 4). The indicators nonrec and nonproximate are associated with no (nontrivial) variance in WTP. This result indicates that the use behaviors that might influence WTP for mosquito control are, at the very least, uncorrelated with the nonuse indicators nonrec and nonproximate. More broadly, there may be few observable use behaviors that one might associate with WTP for large-scale coastal wetland mosquito control.

[40] Such results highlight the difficulty in assigning traditional distinctions (e.g., use versus nonuse; user versus nonuser) to WTP for attributes such as mosquito control, with which few observable behaviors may be associated. For such goods, traditional distinctions, while perhaps appealing from certain perspectives, may not be empirically meaningful. In such instances, researchers may find distinctions such as those proposed by Carson et al. [1999] and Mäler et al. [1994] to be more appropriate. These authors have proposed discarding the traditional, but perhaps less empirically tractable, distinction between use and nonuse (or user and nonuser) values in favor of distinctions based purely on relationships to observable market goods. As noted by Freeman [2003, p. 146], however, this recommendation may not be entirely feasible given the ubiquity of "use/nonuse terminology in the literature" and in applied benefit cost analysis.

[41] Finally, while many attributes reveal expected patterns in which a greater scope of use is associated with larger WTP estimates (Table 3), such findings are not universal. For example, WTP for increases in the size of restored wetlands (acres) is similar for users (nonrec $=0$; nonproximate $=0$ ) and complete nonusers (nonrec $=1$; nonproximate $=1)$. However, WTP is reduced for recreational nonusers $($ nonrec $=1$; nonproximate $=0)$. These differences are statistically significant (Table 4), and suggest that additional acres of restored wetlands may be associated with elements (e.g., flooding, wildlife nuisance, development restrictions) that reduce utility for households in close proximity (i.e., for whom nonproximate $=0$ ). As a result, wetland acres have a higher marginal value for those who do not live in close proximity, all other things being equal.

[42] These patterns illustrate somewhat counterintuitive case, that of restored wetland acres, in which a greater scope of use is not associated with greater WTP. Moreover, such results are not apparent if one considers nonuser definitions based solely on the absence of recreation. Given a solely recreational definition of nonuse, one would draw the standard conclusion that user WTP exceeds nonuser WTP for all wetland attributes (Table 3, columns 2 and 3). The sole exception would be WTP for mosquito control, which is nearly identical for both users and nonusers. The additional insight provided by a more nuanced definition of resource use (here that proximity to wetlands is associated with reduced marginal WTP for restored acres) points to further limitations associated with the identification of nonusers based solely on the absence of recreational uses.

\section{Conclusion}

[43] While model results are based on a single case study, they suggest that distinctions between user and nonuser values may be subject to a high degree of variance in reliability and interpretation, depending on the specific characteristics of the resources in question and the mechanisms used to distinguish users from nonusers. For many wetland attributes, WTP differences between users and nonusers follow expected patterns, but are not statistically significant. Moreover, the statistical significance of WTP differences is sensitive to mechanisms used to define nonusers. We also find evidence that for attributes such as mosquito control, the use underlying presumed user WTP may defy simple measurement, leading to cases where the distinction between user and nonuser WTP may have questionable empirical justification.

[44] Still more difficult to identify and estimate would be off-site or indirect use WTP, particularly in cases where those using wetland services have little knowledge that the 
quality of activities (e.g., fishing) depends in part on services provided by distant coastal wetlands. Similarly complex would be cases in which the user or nonuser status of individuals is endogenous with respect to policies considered by a stated preference instrument or benefit cost analysis. While not addressed by the present empirical application, such situations highlight yet additional challenges in the applied decomposition of user and nonuser values.

[45] Such issues may be of particular concern in cases where benefit cost analyses combine user values estimated using revealed preference methods with nonuser values estimated using stated preference techniques. Here, the risk of either double counting or failing to include certain benefits is greater if definitions of resource users are ambiguous. Model results also suggest that decompositions of user and nonuser values may be fundamentally noncomparable across different study contexts. Such issues may be particularly germane for cases in which benefit transfer is applied to approximate user and nonuser values based on research conducted elsewhere.

[46] While our results suggest that the skepticism of some researchers toward WTP decomposition may be well founded [e.g., Cummings and Harrison, 1995], we emphasize that results shown here do not suggest that researchers abandon measurement of user and nonuser values. Nonetheless, results do suggest caution in the interpretation of such results, and in comparing distinctions between user and nonuser values across study contexts, particularly where researchers apply unlike methods to define nonusers. Results also suggest that researchers consider the possibility that certain types of WTP typically classified as use values (e.g., values for mosquito control) may lack a discernable correlation to observable behaviors. In such cases, reported nonuser WTP may contain components that some researchers might consider to be use values, and traditional distinctions between use and nonuse values may be less appropriate. Finally, model results suggest the potential benefit of additional research into the implications of different mechanisms used to define resource users and nonusers, particularly those encountered frequently in applied benefit cost analyses.

[47] Acknowledgment. This research was funded by the National Science Foundation STAR Grant Program, the Connecticut Sea Grant College Program, and the University of Rhode Island Agricultural Experiment Station (AES 5015).

\section{References}

Adamowicz, W., P. Boxall, M. Williams, and J. Louviere (1998), Stated preference approaches for measuring passive use values: Choice experiments and contingent valuation, Am. J. Agric. Econ., $80,64-75$.

Arrow, K., R. Solow, E. Leamer, P. Portney, R. Rander, and H. Schuman (1993), Report of the NOAA Panel on Contingent Valuation, Fed. Regist., 58, 4602-4614.

Boyer, T., and S. Polasky (2004), Valuing urban wetlands: A review of nonmarket valuation studies, Wetlands, 24(4), 744-755.

Carson, R. T., N. E. Flores, and R. C. Mitchell (1999), The theory and measurement of passive-use value, in Valuing Environmental Preferences: Theory and Practice of the Contingent Valuation Method in the US, EU, and Developing Countries, edited by I. J. Bateman and K. G. Willis, pp. 97-130, Oxford Univ. Press, New York.

Croke, K., R. G. Fabian, and G. Brenniman (1986), Estimating the value of improved water quality in an urban river system, J. Environ. Syst., 16(1), $13-24$.
Cronin, F. J. (1982), Valuing nonmarket goods through contingent markets, Rep. PNL 4255, Pac. Northwest Lab., Richland, Wash.

Cummings, R. G., and G. W. Harrison (1995), The measurement and decomposition of nonuse values: A critical review, Environ. Resour. Econ., $5,225-247$.

Freeman, A. M., III (2003), The Measurement of Environmental and Resource Values: Theory and Methods, Resour. for the Future, Washington, D. C.

Greene, W. H. (2002), NLOGIT version 3.0 reference guide, Econ. Software, Inc., Plainview, N. Y.

Greene, W. H. (2003), Econometric Analysis, 5th ed., Prentice-Hall, Upper Saddle River, N. J.

Griffiths, C. (2002), The use of benefit-cost analysis in environmental policy making, paper presented at Economic Valuation of Health for Environmental Policy: Assessing Alternative Approaches, Univ. of Cent. Fla., Orlando, 18-19 March.

Hanemann, W. M. (1984), Welfare Evaluations in contingent valuation experiments with discrete responses, Am. J. Agric. Econ., 66, 332341.

Johnston, R. J., G. Magnusson, M. Mazzotta, and J. J. Opaluch (2002), Combining economic and ecological indicators to prioritize salt marsh restoration actions, Am. J. Agric. Econ., 84, 1362-1370.

Johnston, R. J., E. Y. Besedin, and R. F. Wardwell (2003a), Modeling relationships between use and nonuse values for surface water quality: A meta-analysis, Water Resour. Res., 39(12), 1363, doi:10.1029/ 2003WR002649

Johnston, R. J., S. K. Swallow, D. Marie Bauer, and C. M. Anderson (2003b), Preferences for residential development attributes and support for the policy process: Implications for management and conservation of rural landscapes, Agric. Resour. Econ. Rev., 32(1), 65-82.

Layton, D. F. (2000), Random coefficient models for stated preference surveys, J. Environ. Econ. Manage., 40(1), 21-36.

Maddala, G. S. (1983), Limited Dependent and Qualitative Variables in Econometrics, Cambridge Univ. Press, New York.

Mäler, K. G., I. M. Gren, and C. Folke (1994), Multiple use of environmental resources: A household production function approach to valuing natural capital, in Investing in Natural Capital: The Ecological Economics Approach to Sustainability, edited by A. M. Jansson et al., pp. $233-$ 249, Island, Washington, D. C.

McConnell, K. E. (1983), Existence and bequest value, in Managing Air Quality and Scenic Resources at National Parks and Wilderness Areas, edited by R. D. Rowe and L. G. Chestnut, pp. 254-264, Westview, Boulder, Colo.

McConnell, K. E. (1990), Models for referendum data: The structure of discrete choice models for contingent valuation, J. Environ. Econ. Manage., 19(1), 19-34.

McFadden, D., and K. Train (2000), Mixed multinomial logit models for discrete responses, J. Appl. Econ., 15(5), 447-470.

Mitchell, R. C., and R. T. Carson (1981), An experiment in determining willingness to pay for national water quality improvements, research report, U.S. Environ. Prot. Agency, Washington, D. C.

Olsen, D., J. Richards, and R. D. Scott (1991), Existence and Sport values for doubling the size of Columbia River Basin salmon and steelhead runs, Rivers, 2, 44-56.

Randall, A., and J. R. Stoll (1983), Existence value in a total valuation framework, in Managing Air Quality and Scenic Resources at National Parks and Wilderness Areas, edited by R. D. Rowe and L. G. Chestnut, pp. 265-274, Westview, Boulder, Colo.

Schkade, D. A., and J. W. Payne (1994), How people respond to contingent valuation questions: A verbal protocol analysis of willingness to pay for an environmental regulation, J. Environ. Econ. Manage., 26(1), $88-109$.

Train, K. (1998), Recreation demand models with taste differences over people, Land Econ., 74(2), 230-239.

U.S. Environmental Protection Agency (USEPA) (2000a), Guidelines for preparing economic analyses, Rep. EPA 240-R-00-003, Off. of the Admin., Washington, D. C.

U.S. Environmental Protection Agency (USEPA) (2000b), Economic and environmental impact assessment of proposed effluent limitations guidelines and standards for the coal mining industry: Remining and western alkaline subcategories, Rep. EPA 821-B-00-002, Off. of Water, Washington, D. C.

U.S. Environmental Protection Agency (USEPA) (2003a), National pollution discharge elimination system-Proposed Regulations to establish requirements for cooling water intake structures at Phase II existing facilities: Notice of data availability, Fed. Regist., 68 , $13,567-13,575$ 
U.S. Environmental Protection Agency (USEPA) (2003b), Economic and environmental benefits analysis document for the final effluent limitations guidelines and standards for the metal products and machinery point source category, Rep. EPA-821-B-03-002, Off. of Water, Washington, D. C.

Whitehead, J. C., and G. C. Blomquist (1991), A link between behavior, information, and existence value, Leisure Sci., 13, 97-109.

Whitehead, J. C., and P. A. Groothuis (1992), Economic benefits of im proved water quality: A case study of North Carolina's Tar Pamlico River, Rivers, 3, 170-178.

Whitehead, J. C., G. C. Blomquist, T. J. Hoban, and W. B. Clifford (1995), Assessing the validity and reliability of contingent values: A comparison of on site users, off site users, and non users, J. Environ. Econ. Manage., 29(2), 238-251.

R. J. Johnston, Department of Agricultural and Resource Economics, University of Connecticut at Avery Point, 1080 Shennecossett Road, Groton, CT 06340-6048, USA. (robert.johnston@uconn.edu)

J. J. Opaluch and G. Magnusson, Department of Environmental and Natural Resource Economics, University of Rhode Island, Kingston, RI 02881, USA.

M. J. Mazzotta, 10 Kickapoo Run, Charlestown, RI 02813-3410, USA. 